\title{
Reassessing Political Explanations for Murders of Police
}

\author{
Robert J. Kaminski \\ Department of Criminology and Criminal Justice \\ University of South Carolina \\ E-mail: kaminskb@gwm.sc.edu
}

Thomas D. Stucky

School of Public and Environmental Affairs, Indiana University Purdue University at Indianapolis

E-mail: tstucky@iupui.edu.

This is the author's manuscript of the article published in final edited form as:

Kaminski, R. J., \& Stucky, T. D. (2009). Reassessing political explanations for murders of police.

Homicide studies, 13(1), 3-20. http://dx.doi.org/10.1177/1088767908326678

AUTHOR'S NOTE: This research was supported in part by a National Science Foundation grant (\#SES-0002291). We thank David Jacobs for providing us with his dataset and model command statements. 


\section{REASSESSING POLITICAL EXPLANATIONS FOR MURDERS OF POLICE}

Drawing on the racial threat thesis, Jacobs and Carmichael (2002) argued that the overrepresentation of blacks among felons who murder police is in part explained by blacks' conscious or unconscious responses to political subordination by the state. In testing this argument, they found that their key theoretical variable - the presence of a black mayor - was inversely related to police homicides and injurious assaults across many model specifications. This article describes a limited reanalysis of Jacobs and Carmichael's homicide data and additional analyses with a larger sample of cities. Our findings suggest that the significance of the black mayor variable may have been an artifact of model specification. Instead, we find evidence that black city council representation may be associated with reduced homicides of police by blacks. Further research is needed, however, because of the limited explanatory power of key factors highlighted in past research.

KEY WORDS: homicide, police, racial threat, political subordination, economic subordination 


\section{INTRODUCTION}

Although common in other criminological research, few researchers have drawn on conflict theory and the racial threat thesis to explain violence against the police (Chamlin 1989). A recent analysis by Jacobs and Carmichael (2002), however, has increased attention to this perspective. In their article, Jacobs and Carmichael (hereafter J\&C) posited that the overrepresentation of blacks among felons who murder police ${ }^{1}$ is in part explained by their economic and political subordination by the state. According to this view, many killings of police by blacks are a response to subordination in the form of "inarticulate protest" or "primitive rebellion” directed against repressive state agents, i.e., law enforcement officers. Accordingly, homicide rates are expected to be higher in jurisdictions in which blacks are most politically and economically repressed, and lower in jurisdictions in which blacks attain or surpass political and economic parity with whites. In testing this argument, J\&C found that their key theoretical variable - the presence of a black mayor in 11 of 165 cities - was inversely related to police homicides across many alternative model specifications, thus providing strong support for a political argument. J\&C (2002:1243) conclude that “the most theoretically noteworthy results concern economic and political subordination. The number of officers killed is greater in cities where the gap in racial economic resources is most pronounced, but the presence of a black mayor reduces these killings, and neither relationship is trivial.”

This article examines the robustness of J\&C’s key findings. First, we replicate J\&C’s main model using their data and model command statements. Second, after correcting for an apparent error in their specification of their exposure variable (discussed further below), we reestimate the model and find that presence of a black mayor is not statistically significant. Third, we repeat the analysis using a larger sample of cities and more recent data. With this expanded sample, we do not find that the presence of a black mayor reduces the number of killings of police officers by blacks, nor do we find support for the effects of black economic subordination. However, in an extended model we do find support for an alternative political measure, namely the average 
number of city council members that were black.

\section{JACOBS AND CARMICHAEL'S BASIC MODEL}

J\&C’s (2002:236) basic model (Table 2, Model 2) can be described as

$$
\mu_{i} j_{i}=\exp \left(\beta_{0}+\beta_{1} \chi_{1}+\beta_{2} \chi_{2}+\ldots+\beta_{8} \chi_{8}+\ln j_{i}\right)
$$

where $\mu_{i}$ is the expected number of homicides for observation $i, j_{i}$ is an exposure variable for unit $i\left(j=\right.$ number of police officers per city), $\chi_{1}=$ percent black, $\chi_{2}=$ black/white median household income, $\chi_{3}=$ violent crime rate, $\chi_{4}=$ population, $\chi_{5}=$ population squared, $\chi_{6}=$ residential segregation, $\chi_{7}=$ black mayor, $\chi_{8}=$ percent divorced and $\ln j_{i}$ is the natural log of the exposure variable (Long and Freese 2003:264). The key predictions in J\&C’s arguments are that the slope of black/white median household income (economic inequality) will be positive $\left(\beta_{2}^{*}>0\right)$ and the slope for black mayor (political inequality) will be negative $\left(\beta_{7}^{*}<0\right)$. J\&C estimated their model using Poisson regression (Cameron and Trivedi 1998) with the Stata software package (StatCorp 2003).

A key issue in the analysis concerns specification of the exposure variable. Upon examining J\&C's data, it was evident that their exposure variable (t0tswnlg) was logged prior to estimation $(\min =4.51 ; \max =10.06 ;$ mean $=6.04)$. Stata allows normalization for unequal exposure using either an exposure or offset command (or by manually entering the log of the exposure variable with its regression coefficient constrained to equal 1). Offset and exposure accomplish the same thing, with the difference being that exposure is to be used when the exposure variable is not logged and offset is to be used when the exposure variable is already logged (Long and Freese 2003:264-266; StataCorp 2003:205). Since J\&C’s exposure variable was logged, offset is the proper command. However, according to J\&C’s model statements, Stata’s exposure command 
was used instead. ${ }^{2}$ As we demonstrate below, substituting the offset command has important consequences regarding the impact of the presence of a black mayor, a key theoretical variable in their paper.

\section{REPLICATION ${ }^{3}$}

Using the data and model command statements generously provided by $\mathrm{J} \& \mathrm{C}$, we replicate the estimates in their first model to include presence of a black mayor (J\&C’s Table 2, Model 2). We then estimate an alternative model using a different (and we believe appropriate) specification of the exposure variable. Next, we estimate an analogous model using a larger sample of cities and more recent data. Finally, we estimate a model using alternative racial threat and black political representation measures.

J\&C’s sample consisted of 165 cities that had populations greater than 100,000 in 1980 and for which racial segregation scores were available (J\&C 2002:1231). The dependent variable was the sum of the number of local police officers killed feloniously 1981 - $1990(\mathrm{~N}=237)$. Independent variables included 1980 values for population size (divided by 10,000), population size squared (divided by 100,000), the percentage of the population that was black, the log of the violent crime rate, presence of a black mayor in 1980, percent divorced, racial segregation, and the ratio of black-to-white median household income in 1979 (see J\&C 2000:1232 - 1233 for additional details).

\section{Replication Results}

Table 1 presents three sets of Poisson regression estimates (to conserve space only regression coefficients and significance levels are reported). Model 1 replicates J\&C’s estimates, Model 2 presents estimates using the corrected exposure variable, and Model 3 presents results using a larger sample of cities and more recent data (sample and data details provided later). Comparing 
Model 2 to Model 1 shows that although the alternative specification of the exposure variable has only modest impacts on most estimates, the estimate for black mayor is no longer statistically significant ( $p=.162$ ) and its magnitude is substantially attenuated. ${ }^{4}$ Further, the pseudo- $\mathrm{R}^{2}$ value decreases from .43 to .09 with the alternative model specification. Precisely why the $\mathrm{R}^{2}$ value drops so precipitously is not clear as the only difference between the two models is the different specification of the exposure variable, suffice to say the correctly specified model suggests a substantially poorer fit to the data.

\section{Table 1 about here}

J\&C (2002:1246, note 5) argue that a coefficient on a skewed dummy variable typically will be weaker in a multivariate regression analysis and suggest that an increase in the number of cities with black mayors should produce stronger results (11 of 165 cities or $6.7 \%$ had a black mayor in their sample). Twenty-one of 190 cities (11.1\%) in our expanded sample had a black mayor, thus if J\&C are correct we would expect to observe a stronger black mayor effect. As Model 3 shows, however, the presence of a black mayor continues to be statistically insignificant $(p=.973)$ and its estimated coefficient is near zero.

Taken together, the evidence from Models 2 and 3 do not suggest an association between the presence of a black mayor and murders of police. It is also noteworthy that with the exception of percent black, none of the other regressors in Model 3 are statistically significant at the .10 level, suggesting that while racial threat and economic inequality factors may have been associated with police killings in the 1980s, that was no longer the case in the 1990s. Further, although the percentage of the population that was black is significantly and positively associated with felonious killings of police across all three models, a simple linear effect does not provide convincing evidence in support of political threat arguments (Blalock 1967; Eitle et al. 2002; Horowitz 1985; Jackson 1989). We expand on this point in the next section, where we extend J\&C’s analysis and provide a more comprehensive test of political explanations for murders of 
police.

\section{EXTENSION}

In extending J\&C’s model we use an expanded sample of cities and more recent data on police killings. Note, however, that while we include many of the same variables as the previous models, we specify some variables differently. For example, although we include models using J\&C's measure of the presence of a black mayor, we also test alternative versions of the variable. In addition, we test a political factor not considered by J\&C - the number of black city council members - and we include a measure of the racial composition of the police force relative to the racial composition of population served.

\section{Data and Method}

Our sample consists of cities with 1990 resident populations of 100,000 or more served by law enforcement agencies employing 100 or more sworn officers $(\mathrm{N}=190)$. J\&C aggregated their dependent variable, police murdered in the line of duty, over the years 1981 - 1990 . Similarly, we sum the number of police murdered for the years $1985-1995 .{ }^{5}$ As displayed in Figure 1, even after aggregating over a decade, fatal assaults of police remained extremely rare events. (For details regarding the nature and circumstances of murders of police, we refer readers to the FBI's Law Enforcement Officers Killed and Assaulted reports, available at http://www.fbi.gov/ucr/ucr.htm\#leoka.) Cities with the highest counts included New York (20), Chicago (14), Detroit (11) Philadelphia (10), Los Angeles (9), Dallas (8), and Washington, DC (6). The remaining jurisdictions had five or fewer murders of police.

\section{Figure 1 about here}

Given the extreme skew and high zero counts, we estimate our models using Poisson regression (Cameron and Trivedi 1998). ${ }^{6}$ Poisson regression estimates the number of occurrences (or counts) of an event. Typically, it is desirable to incorporate unequal exposure into the model, 
such as time at risk or the size of the population at risk. This is accomplished in our analysis by adding the log of the size of the population (number of sworn field officers) to the model and restraining its coefficient to equal 1 (Long and Freese 2003). With this adjustment, the model becomes an analysis of rates of events per capita (or incidence rate) rather than an analysis of the number of events (Osgood 2000:27). One often wants to compare rates, and this is easily accomplished by calculating incidence rate ratios; the incidence rate ratio for a one-unit change in $x_{\mathrm{i}}$ is (Statcorp 2003:551)

$$
\frac{e^{\ln (E)+\beta_{1} x_{1}+\ldots+\beta_{i}\left(x_{i}+1\right)+\ldots+\beta_{k} x_{k}}}{e^{\ln (E)+\beta_{1} x_{1}+\ldots+\beta_{i} x_{i}+\ldots+\beta_{k} x_{k}}}=e^{\beta_{i}}
$$

Incidence rate ratios (IRRs) may be interpreted as the percentage change in the expected count for a unit increase in an independent variable. An IRR of 0.80 would be interpreted as indicating a 20 percent decrease in the expected number of events given a one-unit increase in an independent variable, holding all other variables constant ((.80 - 1)*100); an IRR of 1.20 would be interpreted as indicating a 20 percent increase in the expected number of events given a oneunit increase in an independent variable, holding all other variables constant $((1.20-1) * 100)$ (Long and Freese 2003). We report IRRs for all Poisson regression output.

Independent variables come from several sources. Social, demographic, and economic variables were obtained from the U.S. Bureau of the Census download page (1990 Summary Tape File 3). ${ }^{6}$ Data on police employment and the racial composition of police departments are from the Bureau of Justice Statistic’s Law Enforcement Management and Statistics (LEMAS) surveys and are averaged over the years 1987, 1990 and $1993 .{ }^{8}$ Justifiable killings of blacks by police are from the FBI's Supplementary Homicide Reports (SHR). ${ }^{9}$ Finally, data on black mayors and black city council members were obtained from volumes produced by the Joint Center for Political Studies (1987, 1988, 1990, and 1991). ${ }^{10}$ Descriptive statistics for the variables 
used in the analysis are displayed in Table 2.

\section{Table 2 about here}

\section{Key Regressors}

A key element in some prior studies of violence against the police is "racial threat". According to conflict theories of the state, governments engage in activities to maintain control over racial and economic minorities. Subordination of these groups, in turn, creates a sense of injustice that is hypothesized to increase lethal violence directed against state agents (police) (Chamlin 1989; J\&C 2002). Previous studies that employed racial threat concepts included a variety of measures that attempted to capture racial threat, and some focused on the effects of variation in the size of the subordinate population as the source of the threat. For example, J\&C include a measure of the percentage of the population that was black. Therefore, we include a similar measure. Because the logic of the racial threat argument suggests that increasing black populations may be perceived as a threat to majority group dominance and interests, eliciting increased efforts aimed at their control, consistent with $\mathrm{J} \& \mathrm{C}$ we also include a measure of the growth in the percentage of the black population 1980-1990.

Although not included in the original J\&C models, we also include a quadratic term for the percent black measure because Eitle et al. (2002) and others (Blalock 1967; Horowitz 1985; Jackson 1989) argue that the expected relationship between minority threat and social control is nonlinear, although opinions differ on the exact form of this non-linearity. For example, D’Alessio, Stolzenberg, and Eitle (2002) note Blalock (1967) argued that there are two dimensions of racial threat - political and economic. According to D’Alessio et al. (2002), increases in the size of the black population result in greater efforts at control and subordination, but once the size of the black population attains critical mass, blacks should be less subject to the imposition of control due to their increased political or economic power. Under these conditions, one would expect that blacks will be less likely to fatally assault police. If the relationship is 
curvilinear, the sign of the coefficient for percentage black should be positive and the sign for its square should be negative and statistically significant.

Others, however, argue that Blalock (1967) identified different forms of nonlinear relationships depending on the type of competition. According to Tolnay, Beck, and Massey (1989), Blalock (1967) argued that both kinds of threat are expected to increase social control activities by the majority with increases in the size of the Black population - which would then lead to increased conflict and violence against police - but that economic threat should exhibit a positive but decreasing slope, whereas political threat should exhibit a positive but increasing slope. In any event, evaluation of such arguments requires the inclusion of a quadratic term for percent black.

Arguing that higher levels of economic subordination of blacks would be associated with higher levels of violence against the police, J\&C (2002 also include the ratio of black-to-white median household income as a direct measure. Like black population size, the relationship is expected to be curvilinear (Eitle et al. 2002). We therefore include the square of black-to-white median household income to test arguments discussed above regarding the nonlinear nature of such effects.

According to J\&C, increases in black political efficacy may reduce feelings of injustice by blacks and consequently violence against police. To capture increases in black political efficacy, J\&C (2000:1246, note 5) include a dummy indicator of the presence or absence of a black mayor in 1980. Mayoral terms, of course, can vary substantially, lasting only a year, a full four years, or a decade or more, and basing the measure on a single year adds error to a model where the outcome spans a decade. Although we do not have information on black mayors for all years over the study period, we make a modest improvement on J\&C’s measure by including the number of years cities had a black mayor for the period 1987-1991 (excluding 1989 because the reference source for 1989 was unavailable).

Although black mayors are one avenue for providing representation of black interests in local 
government, a substantial body of research suggests that black city council representation may also be important (see e.g. Shihadeh and Flynn 1996:1337). Studies have shown that, among other effects, both black city council representation and the presence of a black mayor are associated with the creation of civilian police review boards (Browning, Marshall, and Tabb 1984; Salzstein 1989) and increased black police employment (Dye and Renick 1981; Kerr and Mladenka 1994; Salzstein 1989). Such tangible impacts on police agencies are likely to reduce the perception among black residents of the police as an occupation force. Therefore, consistent with J\&C’s arguments about the effects of black mayors, we include a second measure of black political strength, which is the average number of black city council members for the years 19871991 (excluding 1989 as noted above).

An important additional measure that we include is the average of the percentage of the police force that was black for the years 1987, 1990, and 1993 divided by the percentage of the population that was black in 1990. Research has consistently shown that blacks hold less favorable opinions of police than do other minorities and whites (Brown and Benedict 2002). However, there is evidence to suggest that blacks’ views of police are far more positive when their representation on the police force approximates that of the resident population (Frank, Brandl, Cullen, and Stichman 1996). Thus, in these jurisdictions police should be viewed less as repressive state agents and blacks should therefore be less likely to fatally assault officers. Values less than 1.0 on this measure indicate black underrepresentation on the force relative to their numbers in population, values near one indicate approximate parity, and values greater than one indicate black overrepresentation relative to their numbers in the population.

\section{Controls}

Like J\&C, we include the violent crime rate, racial segregation, percent divorced, and police justifiable killings of blacks as controls, but unlike J\&C we use composite measures of economic conditions and population structure. The two composite variables were extracted through 
principal components analysis using Census measures of poverty, unemployment, and median household income (component 1), and population size and density (component 2). ${ }^{11}$ Regional differences are controlled through the inclusion of a dummy variable indicating city location in the Northeast. ${ }^{12}$

\section{RESULTS}

Table 3 presents the results of the Poisson regression analysis. Model 1 includes only linear terms for all regressors, while Model 2 includes quadratic terms for percent black and black-towhite median household income. Because diagonal entries from Model 1's hat matrix indicated two potentially high-leverage observations (Cameron and Trivedi 1998:150), we reestimated Model 1 after removing those cases to observe the impact on the obtained estimates. ${ }^{13}$ These results are presented in Model 3.

With respect to J\&C’s key explanatory variables, the regression estimates continue to show no effect for the presence of a black mayor $(p=.594)$. Because this was a critical theoretical variable we tested two additional specifications; the presence of a black mayor in 1990 (J\&C’s specification) and a dummy indicator of the presence of a black mayor at any time $1987-1991$. In addition, we tested several interaction effects. ${ }^{14}$ None of these alternative specifications produced statistically significant effects. Thus, the presence of a black mayor does not appear to be a robust predictor of killings of police by blacks. Interestingly, the average number of black city council members is statistically significant $(p \leq .017)$ and in the expected direction in all three models, with Model 1 suggesting that each increase in the average number of black council members is associated with a five percent decrease in the expected number of police murders. Thus, we find evidence to support political explanations of police killings, though not in the form espoused by J\&C..$^{15}$

\section{Table 3 about here}


The other key finding from J\&C was that black/white income inequality was positively associated with homicides of police. We do not find support for such an argument in the models shown in Table 3. The black/white income variable is not statistically significant $(p=.419)$ in Model 1. The inclusion of a quadratic term in Model 2 does not change the substantive conclusion that black/white income inequality is not a robust predictor of killings of police. ${ }^{16}$

Racial threat arguments do receive some support in the statistically significant $(p=.012)$ effect for percent black; each 10 percent increase in the size of the black population is associated with a 17 percent increase in the expected number of police homicides. Yet, Model 2 does not suggest that this relationship is non-linear, as the coefficient for percent black squared is not statistically significant. Among the remaining regressors, only city location in the Northeast is nearly significant at the .10 level ( $p=.106)$, suggesting that police risk of being murdered in the line of duty in large cities in this region may be nearly 40 percent lower than for those working in large cities in other regions. The lack of significant findings for the structural variables included in the model is somewhat puzzling. We explore some possible reasons for this pattern of findings below.

To determine whether high leverage cases influenced results, we reestimated Model 1 after excluding those observations (Model 3). As can be seen in Model 3, conclusions are largely unchanged. The change in the percentage of the black population, black-to-white median household income, and the presence of a black mayor continue to be statistically insignificant, while the percentage black and the average number of black city council members remain statistically significant. The one notable difference is that the number of justifiable killings of black offenders by police is highly significant, suggesting that each justifiable homicide by police was associated with a five percent increase in the expected number of homicides of police.

To assess the impact of the high leverage cases on the quadratic terms for percentage black and black-to-white median household income, we reestimated Model 2 after their removal (estimates not shown). Results were similar to those of Model 2 - neither quadratic term was 
significant.

Multicollinearity was assessed by examining variance inflation factors (VIFs). All VIFs were less than 4.72 in models excluding the quadratic terms (Models 1 and 3). As expected, the inclusion of the quadratic terms in Model 2 produced high VIFs (VIFs $\cong 16.0$ for percentage black and its square and VIFs $\cong 45.0$ for black-to-white median household income and its square). Therefore, we also tested centered versions of these variables. Although the size of the VIFs were substantially reduced (all VIFs $<5.74$ ), conclusions regarding the impacts of the variables remained unchanged.

\section{CONCLUSIONS}

Our analysis produced four important findings regarding political explanations for violence against the police. First, our replication of J\&C's model - using their data and model commands but with an alternative and (we argue more appropriate) specification of the exposure variable did not suggest support for their conclusion that the presence of a black mayor reduced fatal assaults on police during the 1980s. Additional analyses using a larger sample of cities and more recent data also failed to find an effect, regardless of how we measured the presence of a black mayor (whether as a direct or interaction effect).

Second, in our extension of J\&C’s model, we found that the average number of black city council members was significantly and inversely related to killings of police across all models. Thus, there is evidence that black political representation may reduce police killings by blacks. This finding is generally consistent with J\&C's arguments about the effects of black political efficacy on black violence against police. One possible explanation for such a finding is that black city council members are especially likely to be elected in cities where they represent certain sections of the city (wards) that are likely to have high concentrations of blacks rather than the city as a whole (see Welch 1990; Welch and Bledsoe 1988 for overviews). If this is true, there may be more specific representation of the interests of the black communities most at risk for 
violence against the police in cities with black city council members than in cities with black mayors. This closer link to the government would be expected to increase black political efficacy and the resources to neighborhoods represented by black council members. Clearly, further research is necessary to sort these issues out, particularly given that our measure of black city council representation covers 1987-1991, while the dependent variable spans the 1985-1995 period.

Third, we did not find the measure of black-white economic inequality to be a robust predictor across samples. Although significant in our replication of J\&C’s original model (with the alternative exposure variable specification), this variable did not retain a direct effect on police killings in the expanded sample. In addition, contrary to our expectations based on racial conflict theory (Blalock 1967; Eitle et al., 2002; Jackson 1989), we did not find a nonlinear effect of racial economic inequality on police killings.

Fourth, while the percentage of the population that was black was consistently and positively associated with homicides of police across all models, many racial threat theorists hypothesize the effect of percentage black should be nonlinear (Blalock 1967; Eitle et al. 2002; Jackson 1989). However, the inclusion of a quadratic term produced negligible and statistically insignificant effects. This finding is consistent with some specifications of racial conflict theory but not others. We also did not find that the growth in percent black was associated with increased homicides of police, unlike J\&C.

Further research is needed to tease out the theoretical and empirical effects on homicides of police as a result of "racial threat". The divergence of our empirical findings from J\&C indicates that further empirical research is necessary. Yet, we argue that more theoretical work is needed as well. We noted above that "racial threat" has been measured in a variety of ways and encompasses several dimensions. For example, both D’Alessio et al. (2002) and Tolnay et al. (1989) interpreted Blalock (1967) to suggest nonlinear effects of political threat. However, D’Alessio et al. (2002) argue that the quadratic effect should be negative as social control is 
expected to decrease as the size of the black population attains numerical majority, whereas Tolnay et al. (1989) argue that Blalock (1967) suggests that political threats will lead to increasing social control with an increasing slope. Yet, neither specification of a nonlinear effect was supported in the current study. Of course, one possibility is that the predicted negative and positive slopes for economic and political dimensions might wash out and appear as a more or less linear effect. ${ }^{17}$ Thus, more theorizing to clarify under what conditions one might expect which dimension of "racial threat" to lead to violence against police is warranted.

\section{Figure 2 about here}

It is also notable that the structural factors in J\&C's model (population, racial segregation and percent divorced) retained their significance in Table 1 regardless of how the exposure variable was specified (Models 1 and 2), but not when we estimated the same model using more recent data for the same cities (Table 1, Model 3) or when we estimated a variant of the model using an expanded sample of cities (Table 3). Why these effects are sensitive to the slightly different time frame is not clear, but it may be because of a decline in the number of police killed by blacks during the study period. Figure 2 shows the total number of police murdered and the number murdered by blacks nationally for the years 1981 - 1995. As can be seen, there is a substantial decline in the number of police murdered in the early part of the series, with an even more precipitous drop for police murdered by blacks. ${ }^{18}$ The pattern of killings for the largest .U.S. cities included in this study almost certainly parallels the national pattern, and it may be that the effects of the structural variables observed in J\&C's study depend on the inclusion of the first couple of years of the series during which the counts were substantially higher. Future research explaining temporal trends of murders of police in urban areas might pay special attention to the sensitivity of findings to the inclusion/exclusion of certain years of data.

An additional avenue of research to consider is whether lethal violence begets lethal violence. Although the overall violent crime rate was not a robust predictor of homicides of police, in one 
model we found that justifiable homicides by police were positively associated with killings of police. Such a pattern of findings may suggest that more common kinds of violence such as aggravated assault that largely comprise the violent crime rate may not predict homicides of police well, but that justifiable homicides by police may. Thus, it may be that the willingness to resist police action violently is the key element to consider. In both homicides of police and justifiable homicides by police, lethal violence is the result. The difference may simply be who lost the fight. The willingness to violently resist police may be the result of feelings of injustice such as those described by J\&C, but they also may be a function of other factors not typically discussed in macro-level research, such as prior histories of violence or use of violence more generally. Perhaps another approach would be to consider individual-level research and work up to macro-level theories from the analysis of individual incidents. In any event, the current study shows that much work remains to identify robust predictors of police killings. 


\section{NOTES}

1. African Americans represent about 13 percent of the population, but 43 percent of the felons who kill police (Brown and Langan 2001). This disproportionality, of course, becomes even more extreme if we exclude from the population denominator those unlikely to be police assailants, i.e., the very young, the elderly, and women.

2. The supplied model command statement is poisson polkildt perblk ratmdinh vlcrmrtl popsml pop2esml seg blkmayor perdivrc, $r$ exposure(tOtswnlg) nolog.

3. Note that this is a limited replication in that we only reproduce their second model, whereas J\&C estimated nine models. This is, in part, because J\&C did not provide all the independent variables necessary for replicating some of their latter models, but also because Model 2 captures all key theoretical variables. We also focus our replication on fatal assaults of police, whereas J\&C also examine injurious assaults of police. We focus on fatal assaults of police because they are more far more serious (Kaminski and Sorensen 1995) and are measured with much less error (Kaminski 2002; Margarita 1980a; 1980b).

4. Diagnostic checks on J\&C's (2002) model also showed that the presence of a black mayor was no longer statistically significant following the removal of a single high-leverage observation (Los Angeles). Although it is not always clear what to do under such conditions, it does demonstrate that J\&C's finding regarding the effect of the presence of a black mayor is conditional upon the inclusion of a single observation (results available upon request).

5. Data on police murders were obtained from the hardcopy narratives published in the FBI's Law Enforcement Officers Killed and Assaulted (various years), Washington, DC: Federal Bureau of Investigation.

6. Goodness-of-fit tests suggest the Poisson model is appropriate. We estimated negative binomial regression models as an additional check, but the results were virtually identical.

7. Summary Tape File 3 data can be found at: http://factfinder.census.gov/servlet/DatasetMainPageServlet?_ds_name=DEC_1990_STF3_\&_program=D EC\&_lang=en. One Census-based regressor, black residential segregation, was obtained from David Armstrong, Department of Sociology, The University at Albany, State University of New York. Data were not available for six cities (Columbus, GA; Honolulu, HI; Indianapolis, IN; Jacksonville, FL; Nashville TN, and Providence, RI) and values for these observations were obtained from John MacDonald, Department of Criminology, University of Pennsylvania.

8. The 1990 and 1993 LEMAS data files are from the Inter-University Consortium for Political and Social Research (http://www.icpsr.umich.edu/ICPSR/); the 1987 data were obtained directly by special request from the Bureau of Justice Statistics.

9. Justifiable killings of blacks by police is the number blacks killed per 100,000 black population for the years 1987-1991. The data were obtained from the Inter-University Consortium for Political and Social Research (http://www.icpsr.umich.edu/ICPSR/).

10. We were unable to locate the 1989 edition of the source publication despite exhaustive attempts.

11. All regressors loaded at the .83 or higher level and explained 79.8 percent of the variance.

12. Additional analyses showed that the effect of city location in the South on police homicides was no different from city location in the West or Midwest, hence our decision to contrast these regions with the Northeast.

13. The two high-leverage cases are New York City and Livonia, MI. Estimating Model 2 without these cases had no impact on the insignificant quadratic terms for percent black and B/W income. Model 3 therefore excludes these terms.

14. Black mayor was interacted with centered and uncentered versions of: 1) Black council, 2) Percent black, 3) Black police, 4) Racial segregation, and 5) Economic conditions. (Centering refers to subtracting a variable's mean from each case's value on that variable in order to reduce collinearity between the interaction term and the original variable.)

15. We also examined alternative specifications of the Black city council representation variable. Entering it as the proportion of city council members that were black produced results significant at the .10 level ( $p=.058$ with all observations; $p=.077$ with outliers removed), whereas a dummy variable indicating the presence of at least one black city council member did not approach statistical significance $(p \geq .796)$. Thus, increasing objective numerical strength and to a lesser extent proportional representation of Blacks on the city council, are associated with reduced homicides of police. This finding is also consistent with 
Dye and Renick (1981) who found that objective numerical size of black city council representation was more strongly associated with increased black police employment than a proportional specification. The non-significant effect of the dummy variable could be because cities with large councils but only one Black council member would be coded as 1, but the practical influence of a single Black council member in such circumstances could be quite limited.

16. Because this measure may be affected by the percentages of two- versus one-wage earner households across racial groups, we entered an indicator of black-to-white unemployment rates as an alternative measure of economic competition. However, this measure was statistically insignificant as well, regardless of whether we entered a quadratic term or included or excluded the two high leverage cities (results

available upon request). We thank the editors for pointing out the limitation of the original measure and for suggesting the alternative.

17. We are grateful to the editors for this insight.

18. Explanations for the general decline in killings of police since the mid-seventies despite increases in levels of crime and police employed include more widespread adoption of body armor, improved trauma care, and improved police training and tactics, though attempts to model the impacts of these factors have been unsuccessful (Kaminski and Marvel 2002). 


\section{REFERENCES}

Blaock, H. (1967). Toward a theory of minority group relations. New York: Macmillan.

Brown, B. and Wm R. Benedict. (2002). Perceptions of the police: Past findings, methodological issues and policy implications. Policing: An International Journal of Police Strategies and Management, 25, 543-580.

Brown, J. M. and P. A. Langan. (2001). Policing and homicide, 1976-98: Justifiable homicide by police, police officers murdered by felons. Washington, DC: Bureau of Justice Statistics.

Browning, R., D. R. Marshall and D. H. Tabb. (1984). Protest is not enough: The struggle of blacks and hispanics for equality in urban politics. Berkeley: University of California Press.

Cameron, A.C. and P. K. Trivedi. (1998). Regression analysis of count data. Cambridge, MA: Cambridge University Press.

D’Alessio, S.J., L. Stolzenberg, and D. Eitle. (2002). "The effect of racial threat on interracial and intraracial crimes. Social Science Research, 31, 392-408.

Dye, T.R., and J. Renick. (1981). "Political power and city jobs: Determinants of minority employment." Social Science Quarterly 62:475-486.

Eitle, D., D’Alessio, S.J., and L. Stolzenberg. (2002). Racial threat and social control: A test of the political, economic, and threat of black crime hypotheses. Social Forces, 82, 557-576.

Frank, J., S. Brandl, F. T. Cullen, and A. Stichman. (1996). Reassessing the impact of race on citizens' attitudes toward the police: A research note. Justice Quarterly, 13, 321-34.

Horowitz, D. F. (1985). Ethnic groups in conflict. University of California Press.

Jacobs, D. J., and T. Carmichael (2002). Subordination and violence against state control agents: Testing political explanations for lethal assaults against the police. Social Forces, 80, 1223-1251.

Jackson, P. I. (1989). Minority group threat, crime, and policing. New York, NY: Praeger.

Joint Center for Political Studies. (1987). National roster of black elected officials. Washington D.C.

-----. (1988). National roster of black elected officials. Washington D.C.

------. (1990). Black elected officials, 1990: a national roster. Washington D.C.

-----. (1991). Black elected officials, 1991: a national roster. Washington D.C.

Kaminski, R. J. (2002). An opportunity model of police homicide victimization. Dissertation Abstracts International.

Kaminski, R. J. and D.W.M. Sorensen. (1995). A multivariate mnalysis of individual, situational, and environmental factors associated with police assault injuries. American Journal of Police, 14, 3-48.

Kaminski, R. J. and T. B. Marvell. (2002). A comparison of changes in police and general homicides, 1930 - 1998. Criminology 40, 701-720.

Kerr, B., and K. R. Mladenka. (1994). "Does politics matter? A time-series analysis of minority employment patterns.” American Journal of Political Science 38:918-943.

Long, S. J., and J. Freese. (2003). Regression modes for categorical dependent variables using Stata. College Station, TX: Stata Press.

Margarita, Mona C. (1980a). Criminal violence against police. Ph.D. dissertation, State University of New York at Albany. Ann Arbor, MI: University Microfilms International.

Margarita, M. C. (1980b). Police as victims of violence. The Justice System Journal, 5, 218-233.

Osgood, D. W. (2000) Poisson-based regression analysis of aggregate crime rates. Journal of Quantitative Criminology, 16, 21-43.

Salzstein, G. H. (1989). “Black mayors and police policies.” Journal of Politics 51:525-544.

Shihadeh, E. S., and N. Flynn. (1996). Segregation and crime: the effects of social isolation on the rates of black urban violence. Social Forces, 74, 325-352.

StataCorp. (2003). Stata statistical software: Release 9. College Station, TX: StataCorp LP. 
Tolnay, S. E., E. M. Beck, and J. L. Massey. (1989). Black lynchings: The power threat hypothesis revisited. Social Forces, 67, 605-623.

Welch, S. (1990). The impact of at-large elections on the representation of Blacks and Hispanics. Journal of Politics, 52, 1050-75.

Welch, S., and Bledsoe, T. (1988). Urban reform and its consequences. University of Chicago Press. 
Table 1. Jacobs \& Carmichael's Original Poisson Regression Model, Model after Using Offset (vs. Exposure), and Replication

\begin{tabular}{|c|c|c|c|}
\hline \multirow[b]{4}{*}{ Variable } & \multicolumn{3}{|c|}{ Model } \\
\hline & 1 & 2 & 3 \\
\hline & \multicolumn{3}{|c|}{$\mathrm{J} \& \mathrm{C}$} \\
\hline & $\mathrm{J} \& \mathrm{C}$ & $\begin{array}{l}\text { Of } \\
\text { fse } \\
\text { t }\end{array}$ & $\mathrm{K} \& \mathrm{~S}$ \\
\hline Percent black & $.0269^{3}$ & $.0139^{2}$ & $.0104^{1}$ \\
\hline $\mathrm{B} / \mathrm{W}$ median $\mathrm{HH}$ income & $-1.3973^{1}$ & $-2.1361^{2}$ & -.1780 \\
\hline Log violent crime rate & $.5395^{2}$ & 1584 & 1876 \\
\hline Population & $.0177^{3}$ & $.0031^{1}$ & .0002 \\
\hline Population squared & $-.0018^{3}$ & $-.0004^{1}$ & -.0001 \\
\hline Racial segregation & $-.0304^{2}$ & $-.0332^{2}$ & -1.1950 \\
\hline Black mayor & $-.7162^{2}$ & -.3878 & -.0065 \\
\hline Percent divorced & $.1266^{3}$ & $.1345^{3}$ & -.0034 \\
\hline Constant & $-4.7409^{3}$ & $-5.2554^{3}$ & -7.3620 \\
\hline McFadden's Pseudo $\mathrm{R}^{2}$ & .429 & .086 & .046 \\
\hline
\end{tabular}

Notes: One-tail tests with the exception of racial segregation; $\dagger=p \leq .10 ; 1=p \leq$ $.05,2=p \leq .01 ; 3=p \leq .001$. Significance tests are based on robust standard errors. Population is divided by 10,000; population squared is divided by 10,000,000,000. J\&C = Jacobs \& Carmichael (Table 2, Model 2, p. 1236); J\&C Offset $=$ Model 1 after replacing exposure with offset command; $\mathrm{K} \& \mathrm{~S}=$ our replication. 
Figure 1. Distribution of Dependent Variable

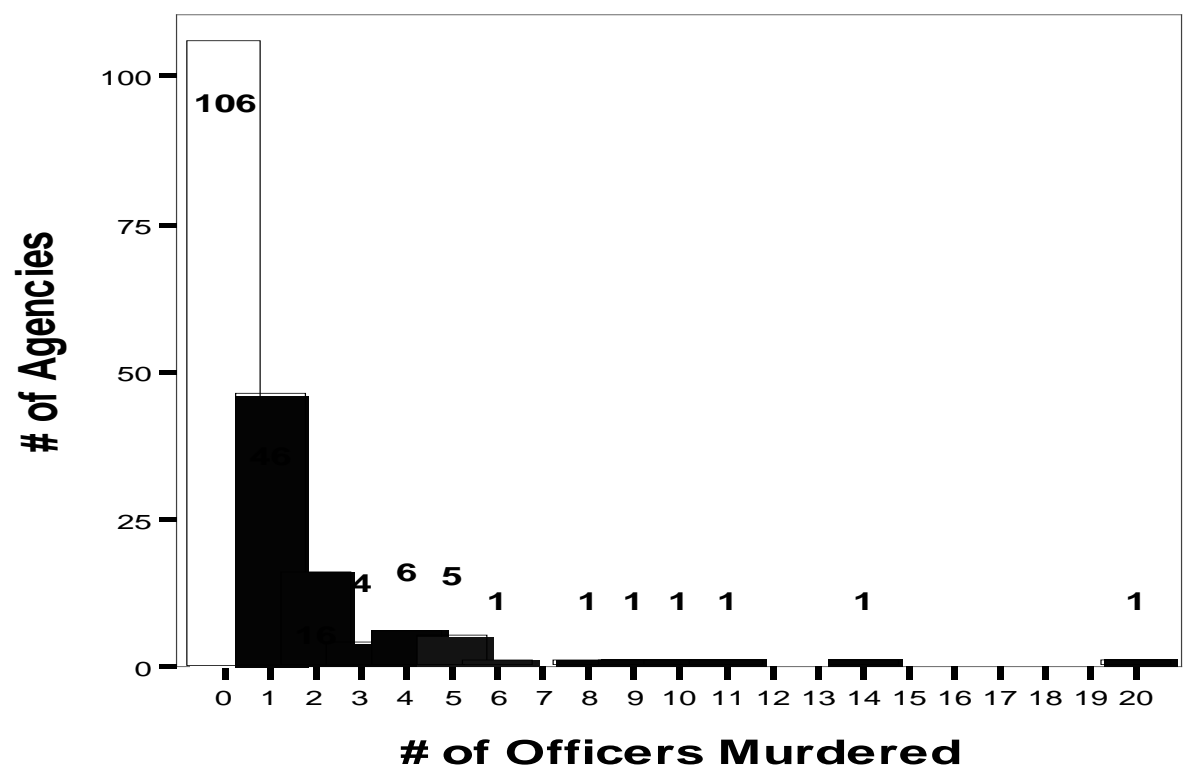

Table 2. Descriptive Statistics for Variables Used in the Analysis

\begin{tabular}{|c|c|c|c|c|c|}
\hline \multicolumn{2}{|l|}{ Variable } & \multicolumn{2}{|c|}{ Min - Max } & \multirow{2}{*}{$\begin{array}{c}\text { Mean } \\
1.14\end{array}$} & \multirow{2}{*}{\begin{tabular}{|c|} 
SD \\
2.43
\end{tabular}} \\
\hline Police homicides (Y) & \# of police murdered 1985-1995 & $0.00-$ & 20.00 & & \\
\hline Northeast & City location in Northeast & $0.00-$ & 1.00 & 0.13 & 0.33 \\
\hline Percent black & \% black pop, 1990 & $0.12-$ & 80.57 & 19.31 & 17.73 \\
\hline Black change & Growth in \% black 1980-90 & $-5.38-$ & 12.70 & 1.72 & 2.53 \\
\hline $\mathrm{B} / \mathrm{W}$ income & Black / white median HH income '89 & $0.78-$ & 3.21 & 1.66 & 0.40 \\
\hline Log violent crime rate & Rate per 100,000 (exc. rape), 1990 & $5.93-$ & 8.91 & 7.72 & 0.58 \\
\hline Population structure & PC of size \& density, 1990 & $-0.95-$ & 9.63 & 0.00 & 1.00 \\
\hline Economic conditions & PC of poverty, unemp, \& income '89 & $-2.52-$ & 2.96 & 0.00 & 1.00 \\
\hline Racial segregation & Dissimilarity index, 1990 & $0.14-$ & 0.88 & 0.52 & 0.17 \\
\hline Black mayor & \# yrs. black mayor '87-'91 & $0.00-$ & 4.00 & 0.46 & 1.13 \\
\hline Black council & Avg. \# black council members '87-'91 & $0.00-$ & 20.00 & 2.08 & 2.87 \\
\hline Percent divorced & \% divorced 1990 & $5.41-$ & 16.14 & 10.12 & 1.88 \\
\hline Black police & Avg. \% blk police '87-'93 / \% blk pop '90 & $0.18-$ & 12.42 & 0.90 & 1.07 \\
\hline Justifiable killings & \# blacks killed per 100,000 black pop & $4.74-$ & 10.15 & 6.03 & 0.94 \\
\hline
\end{tabular}


Field officers (offset) $\quad$ Avg. \# of sworn field officers '87-'93

$108-24,128.00$

4.80

61.10

Notes: 217 police officers were murdered in the line of duty 1985 - 1995; PC = principal component.

Table 3. Poisson Regression of Police Homicides

\begin{tabular}{|c|c|c|c|c|c|c|}
\hline \multirow[b]{2}{*}{ Variable } & \multicolumn{2}{|c|}{ Model 1} & \multicolumn{2}{|c|}{ Model 2} & \multicolumn{2}{|c|}{ Model 3} \\
\hline & $B$ & $p$ & $B$ & $p$ & $B$ & $p$ \\
\hline Northeast & $\begin{array}{r}.6183 \\
(.1838)\end{array}$ & .106 & $\begin{array}{c}.6081^{\dagger} \\
(.1831)\end{array}$ & .099 & $\begin{array}{r}.6073 \\
(.1937)\end{array}$ & .118 \\
\hline Percent black & $\begin{array}{c}1.0175 \\
(.0070)\end{array}$ & .012 & $\begin{array}{l}1.0254 \\
(.0178)\end{array}$ & .149 & $\begin{array}{l}1.0168 \\
(.0077)\end{array}$ & .029 \\
\hline Percent black ${ }^{2}$ & ---- & ---- & $\begin{array}{c}.9999 \\
(.0002)\end{array}$ & .585 & ---- & ---- \\
\hline Black change & $\begin{array}{r}.9783 \\
(.0278)\end{array}$ & .441 & $\begin{array}{c}.9822 \\
(.0288)\end{array}$ & .541 & $\begin{array}{r}.9767 \\
(.0281)\end{array}$ & .412 \\
\hline $\mathrm{B} / \mathrm{W}$ income & $\begin{array}{c}1.6732 \\
(1.0653)\end{array}$ & .419 & $\begin{array}{c}.5840 \\
(1.8824)\end{array}$ & .867 & $\begin{array}{c}1.6044 \\
(1.0508)\end{array}$ & .470 \\
\hline $\mathrm{B} / \mathrm{W}$ income ${ }^{2}$ & ---- & ---- & $\begin{array}{c}2.3020 \\
(5.2988)\end{array}$ & .717 & ---- & ---- \\
\hline Violent crime rate & $\begin{array}{c}1.3953 \\
(.3154)\end{array}$ & .141 & $\begin{array}{l}1.3678 \\
(.3176)\end{array}$ & .177 & $\begin{array}{c}1.4260 \\
(.3280)\end{array}$ & .123 \\
\hline Population structure & $\begin{array}{r}.9569 \\
(.0388)\end{array}$ & .277 & $\begin{array}{c}.9574 \\
(.0379)\end{array}$ & .273 & $\begin{array}{r}.9423 \\
(.0911)\end{array}$ & .539 \\
\hline Economic conditions & $\begin{array}{r}.9804 \\
(.1347)\end{array}$ & .886 & $\begin{array}{c}.9855 \\
(.1384)\end{array}$ & .917 & $\begin{array}{l}1.0020 \\
(.1406)\end{array}$ & .987 \\
\hline Racial segregation & $\begin{array}{r}.8951 \\
(.7320)\end{array}$ & .892 & $\begin{array}{c}.7842 \\
(.6870)\end{array}$ & .781 & $\begin{array}{r}.9292 \\
(.7935)\end{array}$ & .932 \\
\hline Black mayor & $\begin{array}{r}.9655 \\
(.0636)\end{array}$ & .594 & $\begin{array}{c}.9823 \\
(.0694)\end{array}$ & .800 & $\begin{array}{r}.9713 \\
(.0697)\end{array}$ & .686 \\
\hline Black council & $\begin{array}{c}.9480 \\
(.0185)\end{array}$ & .006 & $\begin{array}{c}.9490 \\
(.0189)\end{array}$ & .009 & $\begin{array}{c}.9486 \\
(.0210)\end{array}$ & .017 \\
\hline Percent divorced & $\begin{array}{r}.9405 \\
(.0571)\end{array}$ & .312 & $\begin{array}{c}.9465) \\
(.0579)\end{array}$ & .370 & $\begin{array}{c}.9328 \\
(.0598)\end{array}$ & .278 \\
\hline Black police & $\begin{array}{r}.9240 \\
(.0574)\end{array}$ & .203 & $\begin{array}{c}.9392 \\
(.0686)\end{array}$ & .391 & $\begin{array}{c}.9332 \\
(.0582)\end{array}$ & .267 \\
\hline Justifiable killings & $\begin{array}{r}.9974 \\
(.0017)\end{array}$ & .131 & $\begin{array}{c}.9973 \\
(.0017)\end{array}$ & .124 & $\begin{array}{l}1.0523 \\
(.0139)\end{array}$ & .000 \\
\hline Constant & $\begin{array}{l}-8.6543 \\
(1.7500)\end{array}$ & .000 & $\begin{array}{c}-8.2864 \\
(1.9611)\end{array}$ & .000 & $\begin{array}{c}-8.7528 \\
(1.7528)\end{array}$ & .000 \\
\hline $\begin{array}{l}\text { McFadden's Pseudo } \mathrm{R}^{2} \\
\text { Poisson goodness of fit }\end{array}$ & $\begin{array}{l}.067 \\
\chi^{2}=192.14 \\
p>\chi^{2}(176)\end{array}$ & $=.192$ & $\begin{array}{l}.067 \\
\chi^{2}=192 \\
p>\chi^{2}(1)\end{array}$ & .169 & $\begin{array}{l}.045 \\
\chi^{2}=190.5 \\
p>\chi^{2}(17\end{array}$ & $=.185$ \\
\hline
\end{tabular}

Notes: Two-tailed significance tests based on robust standard errors; $B$ s are incidence rate ratios (i.e., exponentiated regression coefficients); robust standard errors in parentheses; the number of sworn field officers entered as the offset to control for unequal exposure; constants are not exponentiated. 
Figure 2. Number of Law Enforcement Officers Murdered and Number Murdered by Blacks Nationally $1981-1995$

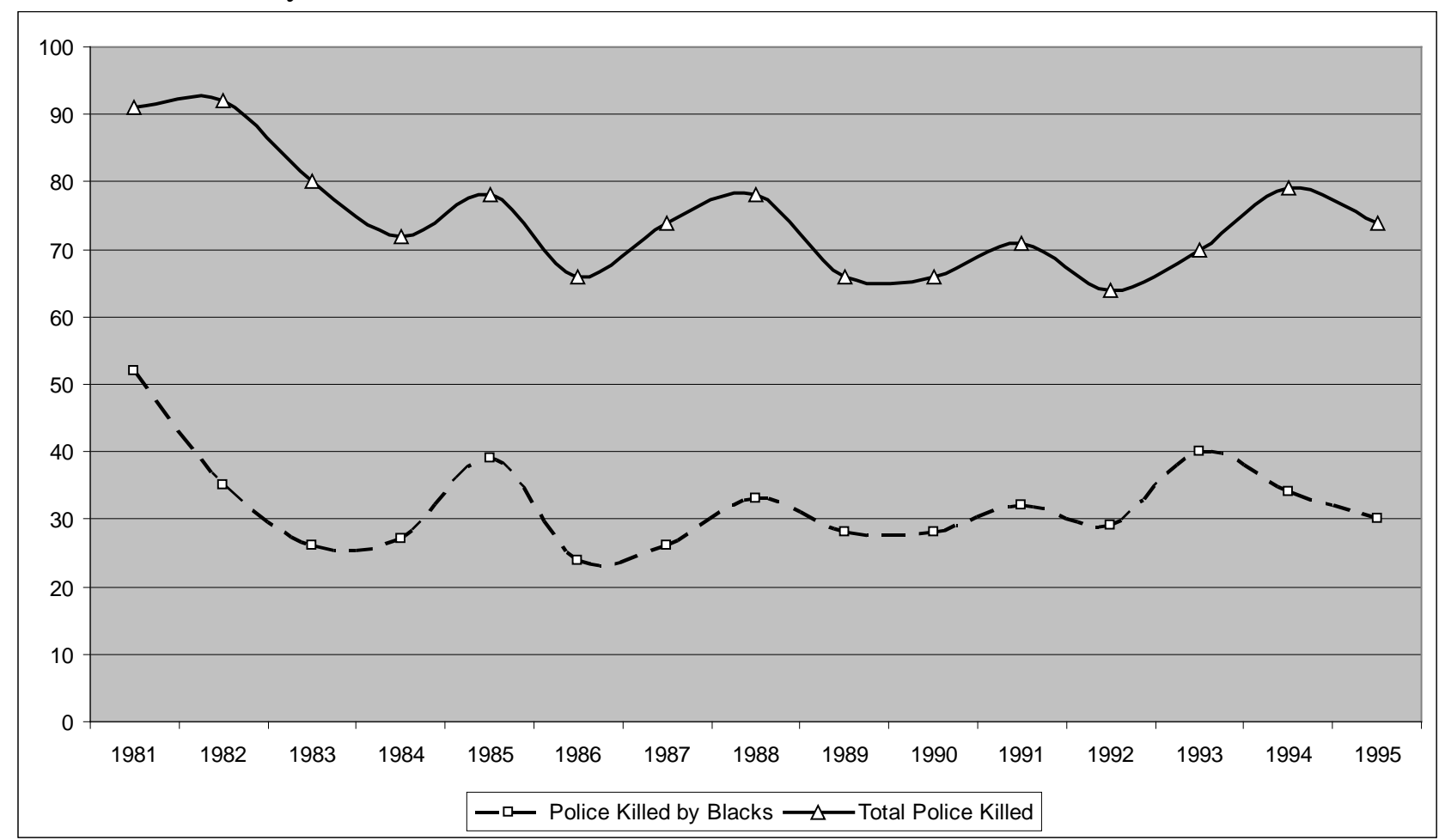

Source: Brown, Jodi M. and Patrick A. Langan. 2001. Policing and homicide, 1976-98: Justifiable homicide by police, police officers murdered by felons. Washington, DC: Bureau of Justice Statistics. 